Family Medicine and Community Health

\section{Critical social framework on the determinants of primary healthcare access and utilisation}

To cite: Hamiduzzaman $\mathrm{M}$, De-Bellis A, Abigail W, et al. Critical social framework on the determinants of primary healthcare access and utilisation. Fam Med Com Health 2021;9:e001031. doi:10.1136/ fmch-2021-001031

\section{Check for updates}

\section{Author(s) (or their} employer(s)) 2021. Re-use permitted under CC BY-NC. No commercial re-use. See rights and permissions. Published by BMJ.

${ }^{1}$ College of Health, Medicine \& Wellbeing, The University of Newcastle, Taree, New South Wales, Australia

${ }^{2}$ College of Nursing and Health Sciences, Flinders University of South Australia, Adelaide, South Australia, Australia

${ }^{3}$ Department of Sociology \& Social Studies, University of Regina, Regina, Saskatchewan, Canada

Correspondence to Dr Mohammad Hamiduzzaman; khoka.hamiduzzaman@ newcastle.edu.au

\section{ABSTRACT}

This paper aims to contextualise 'healthcare access and utilisation' within its wider social circumstances, including structural factors that shape primary healthcare for marginalised groups. Mainstream theories often neglect complexities among the broader social, institutional and cultural milieus that shape primary healthcare utilisation in reality. A blended critical social framework is presented to highlight the recognition and emancipatory intents surrounding person, family, healthcare practice and society. Using the theoretical contributions of Habermas and Honneth, the framework focuses on power relationships, misrecognition/recognition strategies, as well as disempowerment/empowerment dynamics. To enable causal and structural analysis, we draw on the depth ontology of critical realism. The framework is then applied to the case of rural elderly women's primary healthcare use in Bangladesh. Drawing on the literature, this article illustrates how a blended critical social perspective reveals the overlapping and complex determinants that affect primary healthcare utilisation, before concluding with the importance of situating healthcare access in sociocultural structures.

\section{INTRODUCTION}

Recognition and emancipation are connected to equitable and participatory, patient-centred primary healthcare. Access to and utilisation of healthcare generally means the availability of treatments, timely and appropriate treatment, and adequate delivery of services, and in the science of primary healthcare implementation, the emerging concepts are recognition and emancipation of people. ${ }^{12}$ Since the $17 \mathrm{~h}$ century, there has been debate between biomedical and social scientific theories on the conceptualisation of health and healthcare. ${ }^{3}{ }^{4}$ At early stage, medical scientists related health to treatment, which changed when researchers started explaining healthcare using sociological models. ${ }^{5-8}$ This social scientific perspective is supported by biomedical scientists who acknowledge that there are vital aspects of primary healthcare, for example, recognition of patients' needs, preferences and presence; emancipation in participation; and shared decision making, that can only be studied by social sciences, such as social determinants of health. ${ }^{9}$ This paper contextualises a need for a critical social lens into healthcare access, and proposes a critical social framework (CSF) with methodological application to improve primary care support for disadvantaged people.

There are five major paradigms in biomedical and social sciences- biomedical, biopsychosocial, integrated healthcare, health beliefs and social determinants of healtheach of which views healthcare challenges differently. Each model has been developed around the four components of philosophy, structure, process and outcomes. A move from biomedical science to a social determinants of health approach indicates an increase in diversity of philosophies and principles available to accommodate the complexities of healthcare. However, primary healthcare remains inadequate due to lack of conceptualisation of social structures and care accessibility, especially for the underprivileged population groups, for example, rural people, older adults and indigenous people. ${ }^{10}$

The terms 'psychosocial determinants' or 'social determinants' or 'downstream and upstream determinants' are interchangeably used to contextualise an emerging study field of 'healthcare access and utilisation'. This field acknowledges a variety of care system and social circumstances, such as prevention, health communication, rehabilitation, education, poverty and housing, for example, which combine to affect health and care access. ${ }^{10}$ Within a growing academic movement towards better inclusion of determinants not acknowledged by mainstream approaches, there have been reviews of 'causes of the causes' surrounding health and social practices and the exploration of new factors, ${ }^{11-13}$ such as human interactions, recognition, and emancipation. Consideration of deep causes and power structures align with a more critical approach to understand accessibility. 
Box 1 A case-rural elderly women's primary healthcare access in Bangladesh (Hamiduzzaman 2018)

The elderly population is increasing in Bangladesh.$^{50}$ For women in particular, increased longevity coupled with high rates of chronic illness and disability cause specific health needs that have yet to be adequately addressed through primary care services. ${ }^{51}{ }^{52}$ Further, over $70 \%$ of elderly women live in rural areas and these women are less likely than their urban counterparts to seek primary care. ${ }^{2}$ Primary health is expected to be their first point of contact that would cover their care, that is, health promotion, prevention, early intervention, treatment of acute conditions, and management of chronic condition, which are not related to a hospital visit. However, only one rural woman in every 1000 seek primary care and their community clinics visit rate is as low at $5 \%$ of all visits. ${ }^{53}$ In Bangladesh, a pluralist primary care system exists (ie, public, private, and traditional lay treatment options) in rural areas with a disparity in accessing services and poor satisfaction in care support. ${ }^{54}$ Rural women are highly dependent on traditional healing and home remedies provided by semiqualified healers or family members. Limited healthcare utilisation by rural elderly women in this context is shaped by interacting socioeconomic, cultural and political structures. Existing research by the lead author and others noted the significant role of cultural recognition and emancipation in shaping accessibility, ${ }^{44} 55-57$ as the women tend to downplay their own illnesses, delay treatment and depend on lay or traditional healers who may exploit them and/ or provide inappropriate care. Other interconnected barriers for their access include lack of services in rural places; low levels of education and health literacy; and gendered economic inequality-for example, Muslim women inherit only $1 / 8$ of a deceased husband's property and married Hindu women are not entitled to inherit their parents' property. ${ }^{58} 59$ Public income supports for this group are extremely lacking. ${ }^{59}$ The combination of sociocultural, economic and institutional inequalities that shape rural elderly women's primary healthcare access and outcomes in Bangladesh can be best analysed through a critical social science.

Existing literature supports the importance of investigating power differences and personal characteristics in any health facility, family and society. ${ }^{14-17}$ However, application of critical social science in investigating health determinants is complex in either its conceptualisation or actualisation. Several paradigms have been developed in describing healthcare, and there are debates concerning where and how to explore the determinants and their impact on primary care utilisation.

In this paper, we argue that mainstream paradigms and their determinants lack critical engagement with social structures and processes that shape accessibility and outcomes. Drawing on the strengths and limitations of mainstream healthcare paradigms-and positing the importance of a critical social approach informed by the work of Habermas, Honneth and Bhaskar-we develop a theoretical framework for critical analysis of issues in primary healthcare-a CSF. The proposed CSF is developed through a synthesis of existing theoretical approaches; it accounts for social, economic, political and cultural structures and processes that often reflect deeply engrained power differences, misrecognition and marginalisation, while also describing the exploitation of disadvantaged population groups. The causes of poor care accessibility can be seen critically through unpacking and problematising each of the places, events and interactions accounting for the circumstances. ${ }^{18}{ }^{19}$ Based on critical social science, in order to provide a scoping reassessment of existing modes and limitations of the prevailing approaches, the CSF helps to inform a multilayered analysis of primary care for marginalised people. After introducing the CSF, we then apply it deductively to an existing qualitative study of rural elderly women in Bangladesh (box 1: A case), which was conducted by the first author. Through this case study, we apply and assess the utility of the CSF and examine its relevance to primary care practice.

\section{THE PRESENT HEALTHCARE PARADIGMS}

With its origins in western positivism, biomedical science is currently the dominant paradigm to understand personal illness and disease, with two perspectives on treatment: clinical and epidemiological. ${ }^{6}$ While the clinical perspective focuses on the diagnosis of disease and cures for patients, the epidemiological perspective emphasises the

Table 1 Summary of major healthcare paradigms

\begin{tabular}{|c|c|c|c|}
\hline Model & $\begin{array}{l}\text { Dominant } \\
\text { paradigms }\end{array}$ & Focus & Gaps \\
\hline Biomedical & Clinical & Treatment and prevention of disease & $\begin{array}{l}\text { Does not systematically consider } \\
\text { social structures and inequality (eg, } \\
\text { socioeconomic inequality) }\end{array}$ \\
\hline Biopsychosocial & Clinical & $\begin{array}{l}\text { Effects of biological, psychological and } \\
\text { social conditions on health }\end{array}$ & $\begin{array}{l}\text { Limited consideration of (complex) social } \\
\text { factors }\end{array}$ \\
\hline Health beliefs & Behavioural & $\begin{array}{l}\text { Effect of personal health beliefs and } \\
\text { behaviours }\end{array}$ & $\begin{array}{l}\text { Does not consider sociocultural structures } \\
\text { shaping beliefs, behaviours }\end{array}$ \\
\hline $\begin{array}{l}\text { Social determinants of } \\
\text { health }\end{array}$ & Socioecological & $\begin{array}{l}\text { Social, cultural, political and economic } \\
\text { structures }\end{array}$ & $\begin{array}{l}\text { Limited focus on interpersonal power } \\
\text { dynamics (eg, in clinical interactions) }\end{array}$ \\
\hline
\end{tabular}


prevention of disease so that action can be taken to avoid deterioration. ${ }^{20}$ This paradigm often defines the reasons for illness and diseases from a mechanistic outlook without considering socioeconomic aspects. ${ }^{61}$ As such, this model de-emphasises consideration of such factors as the places a person lives and grows as potentially relevant to her/his illness. Koster et al argue that the biomedical paradigm is no longer adequate to explore risk factors that have an impact on healthcare usage. ${ }^{21}$ Although biomedical science is theoretically and practically established, as well as normatively engrained, it has limited value in accounting for the dynamics of healthcare when access to and utilisation of care becomes difficult due to a lack of services, social marginalisation and inequality, or poor socioeconomic circumstances.

A biopsychosocial paradigm emerged as an extended version of the biomedical perspective with the aim of describing healthcare from a patient's biological, psychological and social context. ${ }^{22}$ However, this paradigm remains limited in describing the relationships among mind, body and socioeconomic status of a person. ${ }^{23}$ It highlights the need to consider the effects of psychosocial conditions on an individual, including her/his religious beliefs, work history and previous incidents, for example. Although this approach is considered a means to include social characteristics, it does not provide any direction about which social factors need to be considered along with the psychological and biological factors and, as a result, fails to suggest practical solutions to resist the medicalisation of care. ${ }^{23}$

The integrative healthcare paradigm is a recent addition in biomedical science that focuses on the collaboration of conventional and complementary medical care. This paradigm has been developed based on biological and ecological perspectives, with emphasis on care philosophies, organisational complexity, clinical interactions and other aspects of well-being. ${ }^{24}$ Mann $e t$ al suggest seven dimensions of integrated healthcare including informed clinician, networking clinician, complementary clinician, multidisciplinary group practice, hospital-based integration and integrative care within an academic field. ${ }^{25}$ Another leading perspective in the integrative healthcare paradigm, the 'complex system measure', suggests discussing the illness of a person in a complex and dynamic system. While this paradigm provides a focus on healthcare integration among different types of health professionals and practices, the central aspects of patient's life such as healthcare, emotion, cultural and spiritual needs are less fully considered. Thus, it becomes difficult to explain how health beliefs and behaviours are embodied in a socioeconomic context that also affects care accessibility and utilisation. ${ }^{26}$

In primary healthcare research, the health beliefs and behavioural paradigm appeared from a social scientific stance to guide the investigation of relationships between personal beliefs, characteristics and care seeking behaviours. ${ }^{27}$ Different models in this paradigm provide an understanding about the particular aspects that each person possesses in seeking care. However, these models lack focus on functional system and do not consider that access is also an issue of complex healthcare policy and system measures. ${ }^{28}$ They do not explain how health beliefs and behaviours are rooted in specific sociocultural values of a society. In addition, this perspective is limited in describing the intersections among the determinants where the transformation from potential to realised healthcare access occurs. ${ }^{8}$

The social determinants of health paradigm of WHO (2000) investigates healthcare within the context of larger socioeconomic, political and cultural contexts. ${ }^{29}$ This paradigm describes healthcare according to health behaviours, system and socioeconomic structures and functions that shape the milieu in which people live. ${ }^{29}$ Further categorising social determinants into downstream and upstream determinants provides an understanding of the vertical relationships among the social and healthcare forces. Although each of the determinants have significance based on sociocultural and political realities that emerge horizontally in specific circumstances, these contextual realities were not considered in developing the paradigm. Moreover, the relationships and interactions in health settings and in society emerged as important aspects for accessing healthcare, but the social determinants of health paradigm does not address these issues. ${ }^{30}$ Despite this challenge, recent literature has noted that 'very few public health experts have questioned the Social Determinants of Health theoretical approach itself'. ${ }^{31}$ Accordingly, Frank et al outlined the model's limitations for considering complex problems, relations of power and privilege, and agency at the individual level-thus indicating the importance of both structural and contextual factors. ${ }^{31}$

There are two major drawbacks in the current paradigms (table 1). First, these paradigms tend to downplay the dynamics of relationships and interactions inherent in healthcare access. ${ }^{32}{ }^{33}$ Second, each model conceptualises healthcare from a static point of view as an ideal platform and does not consider how to explore the determinants in everyday healthcare and sociocultural settings. ${ }^{2}$ In addition, primary healthcare is country-specific and diverse in relation to their focus and capacities; for example, WHO (2015) identified that rapid ageing places low/middleincome countries at risk of not coping with the challenges in aged care compounded by the country's primary care policies. ${ }^{10}$ Critical social science has scope to add a sociocultural and political understanding, such as rural elderly women's primary care access and utilisation.

\section{DESIGNING A CSF AND ITS METHODOLOGY}

A CSF, informed by the Frankfurt School of Critical Theory and CR ontology, helps expose the exploitative circumstances that people face because of power structures and their complex inter-relationships exist in a society. ${ }^{34}$ This perspective draws attention, for example, to the socioeconomic structures that operate to oppress 


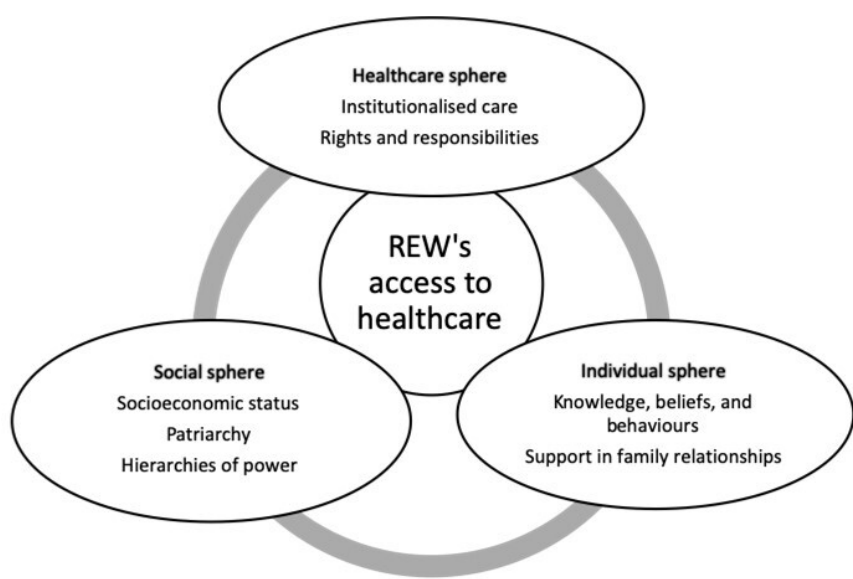

Figure 1 Spheres of a blended critical theoretical framework to contextualise rural elderly women's access to healthcare.

some people while privileging others in a systematic manner. Contemporary critical sciences-which focus on redistribution, equality, emancipation and the recognition of human beings-help reveal the realities of inequitable access conditions for elderly people. ${ }^{10}$ A blended CSF drawing from critical theories of Jurgen Harbermas and Axel Honneth is proposed to address the issues of emancipation and recognition inherent in primary healthcare. ${ }^{18} 193536$ The addition of a depth ontology drawn from CR (eg, Bhaskar 1979), supplements these foci with attention to structural dynamics that cause interactions at multiple levels, including relations of emancipation and recognition.

The Theory of Communicative Action developed by Habermas focuses on emancipation for disadvantaged persons. $^{18} 19$ Habermas introduced a society as a lifeworld including objective, subjective and social worlds that are overlapping with each other. These worlds have potential in describing an individual's communication and emancipation in service utilisation, connection to their personal, institutional and social structures and cultures. ${ }^{19}$ The objective world describes a social actor (a health professional or a patient) who can understand and change existing natural and social structures. ${ }^{18}$ It focuses on the patients' care needs, prevention or early intervention, as well as context-specific treatment and rehabilitation. ${ }^{37}$ The subjective world describes the personal characteristics of a social actor and the totality of their experiences and practices such as behaviours, feelings, values and beliefs that influence their competencies in accessing healthcare. These subjective issues are often reflected in cultural and traditional artefacts or in organised institutions and systems. ${ }^{37}$ Habermas also described a social world through which an actor regulates her or his membership in social groups and structures. ${ }^{19}$ This world is related to the social and institutional order in society such as gender, social class and economic status. This ordered social and or institutional context sets the mode of social interactions and establishes expectations of interpersonal communication, potentially creating a communicative hierarchy among disadvantaged person, healthcare system, and society.

In combination, the three-world concept is a fundamental categorical scaffold that can direct a problematic situation of any society, such as rural elderly women's care accessibility and usage. The concept presents an abstraction of ideas, for example, healthcare system, providerpatient communication, knowledge of actors, personal beliefs and behaviours and socially ordered interactions. However, there are some limitations in this theory: (1) it does not clarify the ideal situation of an emancipatory society $^{37}$; (2) it ignores the capacity of a social actor and how they can meaningfully act in an oppressed situation ${ }^{37}$; (3) while the relationships are identified as important, the issue of relationship remains ignored in the theorisation ${ }^{2}$

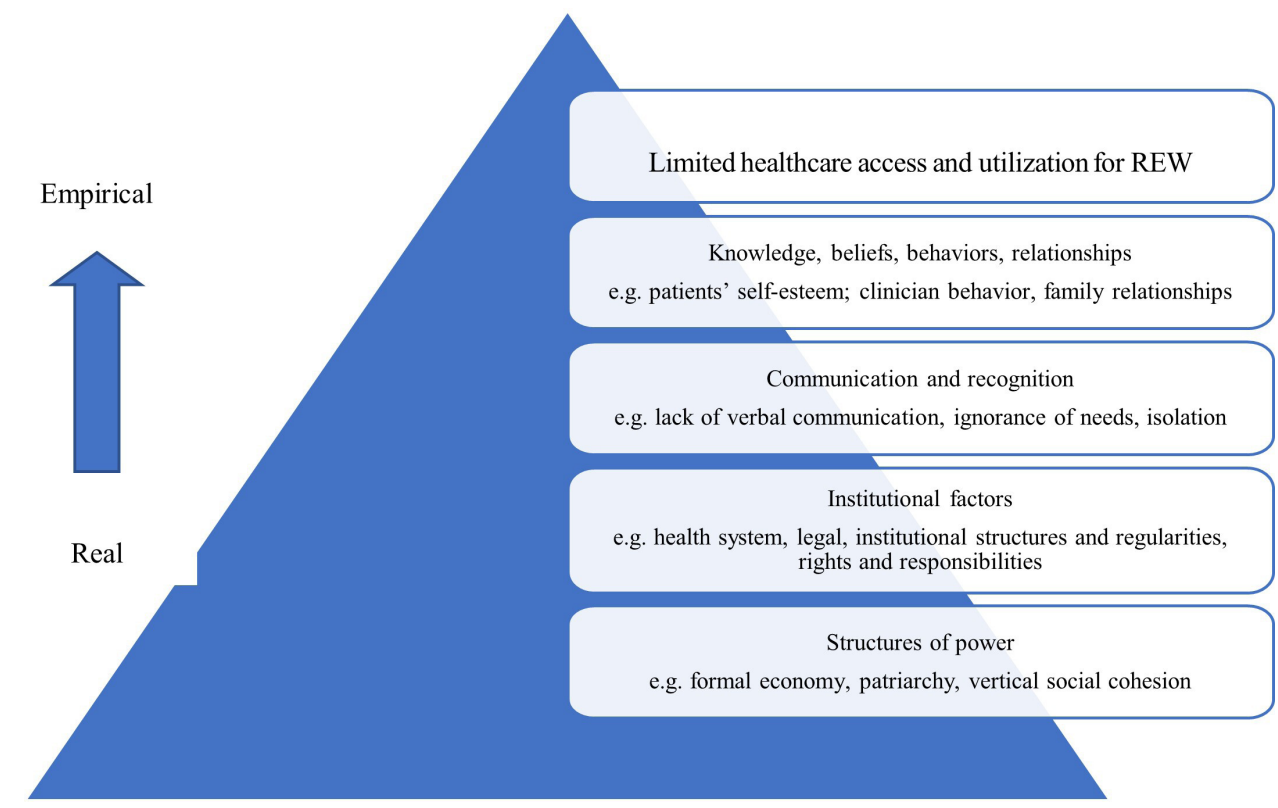

Figure 2 Causal relationships among the determinants of rural elderly women's healthcare access. 


\section{Examples of empirical data}

I wanted to attend school, but could not continue after sixth grade. My parents were not educated, and priority was given to my brothers. My parents wanted to ensure all facilities for my brothers in terms of schooling. Also, village people were against female education on that time. (Rural elderly woman)

I do not see a doctor until my health problems become severe. I did not see a doctor since I started living in this place. I went three times in my life to see a doctor when I failed to bear the pain and/or fever anymore. (Rural elderly woman)

My boys do not live with me-they work in the city and have their own families there. This is a big challenge. If my boys could help, my condition will be good. (Rural elderly woman)

and (4) does not fully consider ontology and causation. More specifically, the approach thus far neglects the emergent effects of pervasive social structures that exist at multiple levels, and therefore, does not allow for identification of specific causal factors that substantially shape people's access to, and experience of, healthcare. These limitations in Theory of Communicative Action can be addressed by considering additional sources-the Theory of Recognition developed by Honneth and a Critical Realist philosophy of science, as originally articulated by Bhaskar-to further explain issues in healthcare. ${ }^{38} 39$

The Theory of Recognition suggests that a person's identity is intertwined with societal recognition. There are three domains of recognition identified: intimate relationships, legal framework and community. ${ }^{35}$ Intimate relationships include both intimate and family relationships, which contribute to the development of mutual respect and positive attitudes to each other through the recognition of a person's needs. ${ }^{36}$ The second domain includes legal relationships or structures that define the rights and responsibilities of a person. For example, freedom from discrimination and misogyny may lead to the development of self-realisation and self-respect for a social actor, allowing them to view themselves as a legally responsible social being with a role to play in society. ${ }^{40}$ This form of relationship also generalises the responsibilities of a health professional to respect and validate the

\section{Examples of empirical data}

In practice, they do not have anything because we obey the decision made by our higher authorities. As you know, we are progressing in maternal and child health ... and have limited scope to ask them to change the focus. (Health professional)

I visited the community clinic and family welfare center few months ago as they are close from my home. I waited there for one hour and returned home without any medications. They suggested me to visit XXX hospital as they only provide care to children and pregnant women. (Rural elderly woman)

In local clinics, we are nothing in front of the doctors and nurses. They will provide you care when they want to, you can't say anything. If someone wants to tell something, there is a chance of not being treated. However, there are some good doctors who called me ma [mother] and I always try to visit them. (Rural elderly woman) needs and rights of persons. Third domain, community recognition, pertains to a person's participation in social structures and activities, which involves shared values and mutual respect. ${ }^{36}$ Community recognition can result in increased self-esteem for the individual, and potentially even models of care that encourage active participation in social and healthcare systems.

The Theory of Recognition has value in the discussion regarding recognition of oppressed or marginalised people. However, it encounters three limitations: (1) ignorance of gender inequality and the role of gender in the economic structure of family and society ${ }^{41} ;(2)$ a lack of focus on reconstruction processes of family and social structures and relationships ${ }^{42}$ and (3) the ongoing challenge of identifying structures that contribute in a casual manner to the experienced marginalisation, both within and beyond the healthcare context. Complex and pervasive sociopolitical structures and systems, patriarchy, for example, are relevant for understanding primary healthcare utilisation. The philosophies and domains of the two theories discussed thus far (Theory of Communicative Action and Theory of Recognition) have a mutual agreement for contextualising access to primary healthcare within the realms of emancipation and recognition. Their mutual focus on the intricacies of power relations, discrimination, and misrecognition in healthcare, social and individual spheres offers a new dimension to understand the determinants and the dynamics in healthcare access and utilisation.

Working towards a blended CSF, figure 1 illustrates the categorisation of six concepts into three spheres, which constitute the subject matter domains of the model. These spheres-all of which should be considered for a holistic analysis-include: (1) knowledge, beliefs and behaviours, as well as support in family relationships under the individual sphere; (2) institutionalised care and rights and responsibilities under the healthcare sphere and (3) socioeconomic status, patriarchy and other power hierarchies under the social sphere.

Despite usefully mapping the domains of analysis, the model thus far lacks fulsome engagement with ontology and causation, which is necessary to examine the full reality of primary healthcare. Drawing from a critical realist philosophy, relations of recognition, emancipation and other aspects of healthcare access are seen to be governed by a particular combination of structural and contextual factors that cause events to occur as they do. ${ }^{39}$ While the two aforementioned theories do engage with aspects of social context beyond the micro level of interaction or interpretation (Honneth's community and Habermas's objective world, eg), there is a need to consider how social structures and deeply rooted power relations contribute to the manifestation of certain outcomes. This kind of methodological analysis is facilitated by a critical realist philosophy, through which the two theories can be deployed.

As a philosophy of science, critical realism asserts a realist ontology (ie, there is a reality) and relativist 


\section{Examples of empirical data}

My sons may give money if they have extra. As they have no extra, they do not give me anything. They have their own families. How could I see a doctor when I have no money? (Rural elder woman)

You cannot imagine how a woman's life moves on. A woman started her life in her father's family, and then she goes for husband's family leaving all relationships with parents, brothers and sisters. I feel that it would be good for me if I could be born as a male in this society. (Rural elderly woman)

My husband used to take all decisions in our family. What are you talking about? Who will take the decision in my family? My elder son lives in the capital city 'Dhaka' and my younger son lives in our previous village. So, all the decisions were made by my husband including my healthcare. (Rural elderly woman)

I do not like to see doctors. Allah is everywhere and Allah will look after me. ... If I suffer from any disease, I know that the health condition will be overcome after a certain period. (Rural elderly woman)

epistemology (ie, there are multiple ways of knowing and explaining the reality). Reality, in this view, is deep and multilayered. ${ }^{38}$ The empirical analysis is the realm of experience, interpretation, and perception, where events are understood through the views of people. Moving deeper, the actual level contains the entirety of the event, whether or not it is understood or perceived. Finally, the real level is the domain of deeply rooted structures and their mechanisms which, if activated in a context, can have an effect at the other levels of reality. In the context of primary healthcare implementation, the addition of a critical realist philosophy allows empirical and theoretical analysis through attribution to causal structures and mechanisms that exist within and shape, the various worlds identified by Habermas and Honneth. Like critical theories, critical realism emphasises the goals of explanation and emancipation, ${ }^{43}$ including identification of structures that cause lack of recognition. At the same time, the critical realist approach usefully asserts an ontological reality on which critiques can be based and alternatives evaluated.

Drawing on the fully developed blended CSF, which considers not only the conceptual spheres but also

Table 2 Translation of the blended CSF into healthcare practice

\begin{tabular}{|c|c|c|c|}
\hline Framework domain & $\begin{array}{l}\text { Relevant framework } \\
\text { spheres }\end{array}$ & Guiding questions: recognition & $\begin{array}{l}\text { Guiding questions: } \\
\text { Emancipation }\end{array}$ \\
\hline $\begin{array}{l}\text { Personal knowledge, } \\
\text { beliefs, behaviours, } \\
\text { relationships }\end{array}$ & $\begin{array}{l}\text { Individual sphere } \\
\text { Healthcare sphere } \\
\text { Social sphere }\end{array}$ & $\begin{array}{l}\text { What agency or capabilities does the } \\
\text { patient have, or lack access to (eg, } \\
\text { education; skills)? } \\
\text { What family supports does the patient } \\
\text { have or lack access to? } \\
\text { What personal belief systems might } \\
\text { facilitate or inhibit healthcare seeking? } \\
\text { Which material resources does the } \\
\text { person have or lack access to (eg, } \\
\text { financial)? }\end{array}$ & $\begin{array}{l}\text { How can the patient's agency } \\
\text { or capacity be enhanced at the } \\
\text { individual level (eg, education)? } \\
\text { How can belief-barriers be } \\
\text { addressed? } \\
\text { How to generate income and } \\
\text { strengthen financial support? }\end{array}$ \\
\hline Communicative factors & $\begin{array}{l}\text { Social sphere } \\
\text { Healthcare sphere }\end{array}$ & $\begin{array}{l}\text { Do these patients experience } \\
\text { misrecognition in everyday life (eg, } \\
\text { within interpersonal relationships)? If } \\
\text { so, in what way(s)? } \\
\text { How might social disadvantage } \\
\text { affect these patients' ability to seek } \\
\text { healthcare? } \\
\text { How might social disadvantage affect } \\
\text { these patients' willingness to seek } \\
\text { healthcare? }\end{array}$ & $\begin{array}{l}\text { How could recognition be } \\
\text { enhanced through changing } \\
\text { communicative practices? } \\
\text { How might misrecognition affect } \\
\text { how these patients are treated } \\
\text { within the healthcare system? }\end{array}$ \\
\hline Institutional factors & $\begin{array}{l}\text { Individual } \\
\text { Healthcare sphere }\end{array}$ & $\begin{array}{l}\text { What structures of communication } \\
\text { might cause these patients to seek, or } \\
\text { not seek, healthcare? } \\
\text { What practices or policies facilitate } \\
\text { recognition or misrecognition? }\end{array}$ & $\begin{array}{l}\text { How could these patients' agency } \\
\text { or capabilities be maximised or } \\
\text { enhanced through institutional } \\
\text { practices or policy changes } \\
\text { (including legal means)? }\end{array}$ \\
\hline Power structures & $\begin{array}{l}\text { Healthcare sphere } \\
\text { Social sphere }\end{array}$ & $\begin{array}{l}\text { How are structural relations of power } \\
\text { and privilege embedded into the } \\
\text { structure of the healthcare system? } \\
\text { Which structural power relations have } \\
\text { contributed to historical marginalisation } \\
\text { (or privilege) of the patient or group (eg, } \\
\text { patriarchy, colonisation, capitalism)? } \\
\text { How do these power relations affect the } \\
\text { patient's rights and responsibilities in } \\
\text { society generally (eg, legal rights)? }\end{array}$ & $\begin{array}{l}\text { How can the effects of } \\
\text { problematic social structures be } \\
\text { mitigated in this context? } \\
\text { How can problematic social } \\
\text { structures be critiqued? } \\
\text { How can problematic social } \\
\text { structures be changed? }\end{array}$ \\
\hline
\end{tabular}


structures and causal relationships (figure 2), this paper now focuses on the application of such a framework to the issue of rural elderly women's primary healthcare in Bangladesh.

\section{STUDYING THE CASE: APPLYING THE CSF FOR PRIMARY HEALTHCARE ACTIONS}

As noted previously, evidence shows that utilisation of primary healthcare is low among rural elderly women in Bangladesh. The data analysed in this paper stem from a study by the first author. ${ }^{2}$ Here, we apply the CSF to consider what is practically happening in this healthcare context, including interactions and practices, as well as broader social, economic and/or cultural structures that shape or determine these interactions. Therefore, a multilevel causal analysis is required. By integrating the spheres of analysis (figure 1) into a depth ontology informed by critical realism (figure 2), a critical methodological analysis of the women's healthcare challenges can be developed. In this applied example, we consider the various components of the phenomenon moving from the empirical level to real/causal and present them in three spheres of CSF, using empirical data excerpted from the first author's study.

\section{Individual sphere (knowledge, individual beliefs, behaviours and relationships)}

Rural elderly women's healthcare access and utilisation is immediately affected by individual-level knowledge, beliefs and behaviours. ${ }^{16} 17$ These beliefs and behaviours are, in turn, influenced by communication, interaction, and relations of recognition of needs. For example, insufficient education for women due to ingrained patriarchal ideologies (lack of recognition) affects the women's knowledge and ability to interact with health professionals and seek information and appropriate care, thus affecting how they are treated in healthcare centres. We believe knowledge makes a woman an active social actor with general understanding, systematic explanation skills and decision-making capacity. Therefore, at this level, education may enable the women to access health information and assist them in choosing and accessing healthcare. Enhanced knowledge and (by extension) increased recognition of the women may also help the professionals to be more accountable and responsible in structuring practice for underprivileged groups like rural elderly women. Our CSF highlights a role for healthcare management and professionals in generalising primary care knowledge. It can also lead to improvements in relations of communication and recognition between care providers and client, as the care provider may come to understand and even help mitigate the barriers their clients face.

We also consider the subjective world of Habermas and the intimate relationships domain of Honneth in explaining the women's healthcare beliefs and behaviours, and contribution of family members in their limited access to healthcare. Our CSF examines personal experiences, feelings, beliefs and behaviours to characterise the limited healthcare access of an elderly woman in Bangladesh. It is noted that a person can only be an active social actor when she or he has capacity to play a role in changing the existing circumstances. Within cultural boundaries, limited education and reduced access to family income and savings, it is difficult for the women to flourish as active social actors and to access healthcare. Their care seeking behaviours are also shaped by socialised roles and expectations, which stem in turn from the deeper patriarchal social structure. These women also experience gendered discrimination in meeting daily needs, including healthcare access. ${ }^{217}$ As such, men and women living in the same family experience the scarcity of resources in very different ways, where men have more rights to use materials such as money and land determined by family members' values and practices.

\section{Institutional sphere (institutionalised care and rights and responsibilities)}

Current health policies and systems in Bangladesh are not designed to meet primary care needs commonly experienced by rural elderly women. ${ }^{14} 4445$ Our CSF includes empirical and theoretical analyses of healthcare policies and healthcare centres in the context of a stratified society. We argue that the critical social science understands the recognition of health needs of underprivileged persons in the context of their functional, clinical, personal and social needs that often include prevention, home care, safe travelling, skilled primary care, psychological services, therapies, social activities and rehabilitation. This perspective challenges the capacity of primary healthcare services relating to staff, equipment, and programmes in providing holistic care. Medical and allied health education and training on gerontology (eg, physiology, pathology, treatment options and preventive measures) and a professional code of ethics that guides clinicians and allied health workers to structure their rights in practice and responsibilities in providing adequate care, should be seen in the context of the health and social policies of a country such as Bangladesh. Another aim of our CSF is to support emancipation of women in seeking regular and complete care, hence, the women's views need to be considered and valued in designing aged care policy and services.

one[]A deeper analysis (figure 2) considers all of the aforementioned issues not only as primary healthcare barriers (and associated solutions), but as products of deeply rooted socio-cultural power structures. For example, relations between patient and care providers are affected by social classification of the professions and male dominance in medical practices in Bangladesh. ${ }^{1544}$ While health professionals are considered to be in positions of power, and health practices are male dominated, marginalisation is common for rural elderly women because they identify themselves as being in an inferior position which negatively influences their 
communications and relationships with care providers. The women are not likely to involve themselves in decisions that concern health knowledge and/or expertise, particularly when mutual trust is essential for sharing health information. ${ }^{46}$ Further, due to patriarchal relations, the women often rely on male family members to assist them in using health services, which may limit their information sharing or may prevent them from seeking care in general.

\section{Social sphere (socioeconomic status and power hierarchy)}

The blended CSF is critical for understanding the historical development of a society (eg, economic condition and social forces and values) for women. The economic status of a woman is related to their employment, family income and savings; economic status is also shaped by financial support from the government and social organisations in Bangladesh. The women's education is largely affected by low family and community education literacy. In this regard, we acknowledge the tenet of 'community recognition' to signify the importance of mutual recognition, honour and support among and between community people and local organisations for developing self-esteem for rural elderly women to enjoy social engagement and economic freedom from early childhood. The reasons of lifelong deprivation among the women in accessing recognition, education, and formal employment are explored by the blended CSF, which contributes to the positioning of a woman in society, as well as in access to primary healthcare.

Power hierarchy strongly emerged in our analysis, encompassing the social order, cultural issues and practices of sociopolitical organisations in rural elderly women's healthcare access. Drawing on critical social science, we argue power difference occurs in dialectical relationships and highlights the tensions, struggles and interplay between contrary tendencies. The social relationships and systems are, therefore, challenged by our CSF in the presence of religious values, distribution of power and political economy of social actions to understand the subject of healthcare in a traditional power structure. Religious values and practices are important in explaining the influence of male dominance at different stages of the women's life including their lack of schooling, unemployment, low income and lack of decision making. Power is generally centralised to the people who have the economic means and position in a cultural and religious structure such as that of Bangladesh. A woman living with her husband and sons has more opportunities to share in the family income and savings than a woman living alone which, in turn, impacts access to healthcare. ${ }^{12}$ The political economy is the basis of making policies and services of socioeconomic and political organisations where the women are seen to have limited value in terms of formal productivity. This social sphere is also related to the individual sphere because a person's beliefs and behaviours are generally shaped in the social environment where the person is born, lives and works.
In this way, we facilitate an empirical and theoretical analysis of patriarchy, socioeconomic marginalisation and other sociocultural power structures that determine a disadvantaged person's recognition and emancipation in primary healthcare. Our CSF incorporates the conceptual meaning of 'society' to explain the process of positioning of a person in social and economic circumstances that impacts access to healthcare. Further, social structures such as patriarchy or socioeconomic marginalisation can be considered basic causes of healthcare access inequality and thereby integrated into the analysis. According to Adams et al, in healthcare settings, there is an opportunity to expand critical social science to explain healthcare of oppressed populations at the professional, institutional and academic levels to ensure better access to primary care. ${ }^{24}$ Use of our CSF in future research on healthcare access in culturally diverse social settings may require adaptation to include key spheres and structures that emerge as most relevant in a given context.

\section{TRANSLATING THE CSF INTO PRIMARY HEALTHCARE PRACTICE}

Here, we describe the translation of the CSF and its methodology into the Johns Hopkins Quality and Safety Research Group's evidence into practice approach, to recognise disadvantaged people's care needs and emancipate them to ensure equitable and participatory primary healthcare. ${ }^{47}$ This approach has four steps. The first step is building an interdisciplinary team to summarise the evidence for a primary care intervention to achieve specific outcomes, by reviewing the extant literature to identify the access barriers and the interventions with greatest benefits. ${ }^{48}$ In second step, the team approaches and engages all stakeholders to understand the context in which the intervention will be implemented. The team's role is to listen carefully and discern what a disadvantaged person may gain or lose from implementing the intervention. The third step includes a development of performance measures to evaluate how often the people access and receive the recommended healthcare. ${ }^{47}$

The final step, in which our CSF and its methodology may play a vital role in engaging the disadvantaged people and their caregivers (family and health professionals), is to design and implement a culturally tailored intervention. We encourage giving voice to the underprivileged people to identify their real-life challenges, at individual, institutional and social spheres, in relation to their healthcare utilisation (Guiding questions: table 2). We also suggest engaging their family caregivers and healthcare providers by sharing their stories of patient misrecognition and marginalisation, and by identifying recognition and emancipation issues at individual, institutional and social spheres for empirical analysis (Guiding questions: table 2). When the events and factors are understood from their views, there is a need for theoretical analysis, that is, the actual level provides an entire picture of healthcare use, and at real level, the interdisciplinary team analyses deeply rooted structures and their mechanisms 
to achieve a scientific perspective into where and how to intervene (figure 2). We encourage the interdisciplinary team to educate all staff and provide training on cultural competence skills to support the proposed intervention, along with concise summaries of access barriers and a checklist of evidence. Designing a culturally tailored toolkit, including two components: create a checklist of care needs, and preventive and care support services, can provide a framework for improving primary healthcare access and utilisation. ${ }^{49}$

\section{CONCLUSION}

This paper has proposed a blended CSF, which combines insights from critical theory and critical realist ontology, to examine access to and utilisation of primary healthcare at multiple levels of analysis. Acknowledging the limitations of mainstream healthcare models in conceptualising healthcare access, the authors highlight the value of CSF to understand multiple contextual and causal factors affecting primary care utilisation for marginalised populations. Focusing on recognition and emancipation, our CSF considers individual, healthcare and social spheres and ultimately identifies basic social structures that shape or determine the phenomenon of healthcare access inequality.

We suggest a new ontological and epistemological insight into human interaction and relationships, knowledge and power structures that are essentially related to a person's access to healthcare. The process of recognition and emancipation, including institutionalisation of care, dynamics of relationships and way of interactions are often not conceptualised within a sociopolitically determined context. While the evolution of major paradigms has not adequately considered sociocultural processes and power relationships, viewing the primary healthcare of rural elderly women in Bangladesh from the blended CSF provides due attention to the institutional, professional, social, cultural and historical forces at play. At present, most low/middle-income countries are undergoing major healthcare policy shifts due to ageing populations, and socioeconomic and structural changes, which are occurring worldwide, and are seeking integrated policies to include healthcare demands of the older generation. Our CSF may contribute an empirical and theoretical explanation to the existing knowledge base. Incorporating the blended CSF in making policies and programmes can shift the dominant biomedical perspective, as well as societal and cultural perspectives, into an integrated model that ensures adequate primary healthcare for disadvantaged populations, particularly in low/middle-income countries.

Acknowledgements We are thankful to Professor Jennene Greenhill, Professor M. Rezaul Islam, Professor Shafiqur Rahman Chowdhury for their valuable feedback on the paper. Also, thanks go to Dr Abraham Kuot and Elspeth Radford for reading the manuscript and contribute to the readability improvement.

Contributors MH accepts full responsibility for the work and/or the conduct of the study, had access to the data, and controlled the decision to publish. MH made substantial contributions to conception and design, acquisition and interpretation of data, drafted the initial manuscript and revising it critically for important intellectual content. AD-B made substantial contributions to conception, design and critical contribution to the manuscript. WA contributed to the conception, design and critically revised the manuscript for important intellectual content. AF revised the manuscript and provided important intellectual content on critical realism.

Funding The authors have not declared a specific grant for this research from any funding agency in the public, commercial or not-for-profit sectors.

Competing interests None declared.

Patient consent for publication Consent obtained directly from patient(s)

Ethics approval This study is approved by Social and Behavioural Research Ethics Committee of Flinders University (Project No. 6705). Participants provided written consent.

Provenance and peer review Not commissioned; externally peer reviewed. Data availability statement All data relevant to the study are included in the article.

Open access This is an open access article distributed in accordance with the Creative Commons Attribution Non Commercial (CC BY-NC 4.0) license, which permits others to distribute, remix, adapt, build upon this work non-commercially, and license their derivative works on different terms, provided the original work is properly cited, appropriate credit is given, any changes made indicated, and the use is non-commercial. See: http://creativecommons.org/licenses/by-nc/4.0/.

ORCID iD

Mohammad Hamiduzzaman http://orcid.org/0000-0001-6027-1564

\section{REFERENCES}

1 Thanassoulis G, Vasan RS. Genetic cardiovascular risk prediction: will we get there? Circulation 2010;122:2323-34.

2 Hamiduzzaman M. The world is not mine: Factors and issues of rural elderly women's access to modern healthcare services in Bangladesh. Doctoral dissertation, South Australia: Flinders University College of Nursing and Health Sciences, 2018. Available: https://theses.flinders.edu.au/view/a4e08c8f-ae46-4c0b-b7c8$47 \mathrm{~d} 54276 \mathrm{a} 448 / 1$

3 Eisenberg L, Kleinman A. The relevance of social science for medicine I. Reidel Publishing Company, 2012.

4 Jones DS, Podolsky SH, Greene JA. The burden of disease and the changing task of medicine. N Engl J Med 2012;366:2333-8.

5 Szreter S, Woolcock M. Health by association? social capital, social theory, and the political economy of public health. Int J Epidemiol 2004;33:650-67.

6 Wade DT, Halligan PW. Do biomedical models of illness make for good healthcare systems? BMJ 2004;329:1398-401.

7 Huber M, Knottnerus JA, Green L, et al. How should we define health? BMJ 2011;343:d4163-63.

8 Bowling A. Research methods in health: investigating health and health services. United Kingdom; McGraw-hill education, 2014. Available: https://www.researchgate.net/profile/lvan-Nyklicek/ publication/232531967_Research_Methods_in_Health/links/54229f8a 0cf26120b7a2130a/Research-Methods-in-Health.pdf

9 Albert M, Laberge S, Hodges BD, et al. Biomedical scientists perception of the social sciences in health research. Soc Sci Med 2008;66:2520-31.

10 WHO. World report on ageing and health, 2015. Available: https:// apps.who.int/iris/bitstream/handle/10665/186463/?sequence $=1$

11 Hamiduzzaman M, De Bellis A, Abigail W, et al. The social determinants of healthcare access for rural elderly women: systematic review of quantitative studies. Open Public Health $J$ 2017;10:244-66.

12 Hamiduzzaman M, De Bellis A, Abigail W. Elderly women in rural Bangladesh: healthcare access and ageing trends. South Asia Research 2018;38:113-29.

13 Hamiduzzaman M, De Bellis A, Abigail W, et al. Social determinants of rural elderly women's healthcare access: a systematic review of qualitative literature. Indian J Soc Work 2018;79:469-96.

14 Hossen A, Westhues A. A socially excluded space: restrictions on access to health care for older women in rural Bangladesh. Qual Health Res 2010;20:1192-201.

15 Hamiduzzaman M, De Bellis A, Abigail W, et al. The world Is not mine - barriers to healthcare access for Bangladeshi rural elderly Women. J Cross Cult Gerontol 2021;36:69-89. 
16 Hamiduzzaman M, Torres S, Fletcher A. Aging, care and dependency in multimorbidity: how do relationships affect older Bangladeshi women's use of homecare and health services? J Women Aging 2021:13:1-4.

17 Hamiduzzaman M, De Bellis A, Abigail W. Exploring the system determinants associated with senior women's access to medical care in rural Bangladesh. Ageing Int 2021;2:1-8.

18 Habermas J. The theory of communicative action. Boston; beacon press, 1984. Available: http://blogs.unpad.ac.id/teddykw/files/2012/ 07/Jurgen-Habermas-Theory-of-Communicative-Action-Volume-1. pdf

19 Habermas J. The theory of communicative action. In: Lifeworld and system: a critique of functionalist reason II. Boston: Beacon Press, 1989.

20 Bahr R, Krosshaug T. Understanding injury mechanisms: a key component of preventing injuries in sport. Br J Sports Med 2005;39:324-9.

21 Koster A, Penninx BWJH, Bosma H, et al. Is there a biomedical explanation for socioeconomic differences in incident mobility limitation? J Gerontol A Biol Sci Med Sci 2005;60:1022-7.

22 Borrell-Carrió F, Suchman AL, Epstein RM. The biopsychosocial model 25 years later: principles, practice, and scientific inquiry. Ann Fam Med 2004:2:576-82.

23 Ghaemi SN. The rise and fall of the biopsychosocial model. $\mathrm{Br} \mathrm{J}$ Psychiatry 2009;195:3-4.

24 Adams J, Hollenberg D, Lui C-W, et al. Contextualizing integration: a critical social science approach to integrative health care. $J$ Manipulative Physiol Ther 2009;32:792-8.

25 Mann D, Gaylord S, Norton S. Moving toward integrative care: rationales, models, and steps for conventional-care providers. Complement Health Pract Rev 2004;9:155-72.

26 Sivertsen N, Harrington A, Hamiduzzaman M. Exploring Aboriginal aged care residents' cultural and spiritual needs in South Australia. BMC Health Serv Res 2019;19:477.

27 Raphael D. Social determinants of health: present status, unanswered questions, and future directions. Int J Health Serv 2006;36:651-77.

28 Norman PA, Conner P. Predicting health behaviour: a social cognition approach. United Kingdom; McGraw-Hill education, 2005. Available: https://edc.iums.ac.ir/files/hshe-soh/files/predicting_Health_beh_ avior(1).pdf\#page $=18$

29 Marmot M, Friel S, Bell R, et al. Closing the gap in a generation: health equity through action on the social determinants of health. Lancet 2008;372:1661-9.

30 Nayar KR, Kapoor SS. Commission on social determinants in health: a piece meal move? Indian J Med Res 2009;129:117-9 https://go. gale.com/ps/i.do?id=GALE\%7CA197413806\&sid=googleScholar\&v= 2.1\&it $=r \&$ linkaccess $=$ fulltext\&issn $=09715916 \& p=A O N E \& s w=w \& c a s a$ token=e3Oa7hCTUukAAAAA:90OKIYUf2PzRTORgBy3xpLbFx2qu 1SN4NDnJNodiASM0audsu5XtJD1vQhejB1j86GWhvn-W6-xdMVSb

31 Frank J, Abel T, Campostrini S, et al. The social determinants of health: time to re-think? Int J Environ Res Public Health 2020;17:5856.

32 Princeton DM. The critical theoretical perspectives and the health care system. RAH 2015;4:72-9.

33 Uddin MN, Hamiduzzaman M. The philosophy of science in social research. J Int Soc Res 2009;2 https://ssrn.com/abstract=1887224

34 Browne C. Critical social theory. London: SAGE Publications Ltd, 2016.

35 Honneth A. Recognition or redistribution? Theory, Culture \& Society 2001;18:43-55 https://journals.sagepub.com/doi/pdf/10.1177/ 02632760122051779?casa_token=EWc5mF4qg6MAAAAA:hgTY XLkCirdODtreNBVsiq-W3JxLsq8ZKzvvKd1zaWR02Z9iN7_A2vE749u 9ShpQaDQ0A6V1xF513YQ

36 Honneth A, Farrell J. Recognition and moral obligation. Social Res 1997;64:16-35 https://www.jstor.org/stable/40971157

37 Greenhalgh T, Robb N, Scambler G. Communicative and strategic action in interpreted consultations in primary health care: a Habermasian perspective. Soc Sci Med 2006;63:1170-87.

38 Bhaskar R. A realist theory of science. London; Verso, 2008. Available: http://uberty.org/wp-content/uploads/2015/09/Roy_ Bhaskar_A_Realist_Theory_of_Science.pdf
39 Bhaskar R. The possibility of naturalism: a philosophical critique of the contemporary human sciences. 4 edn. London: Routledge, 2015.

40 Morken T, Alsaker K, Johansen IH. Emergency primary care personnel's perception of professional-patient interaction in aggressive incidents -- a qualitative study. BMC Fam Pract 2016;17:1-6.

41 McNay L. Social freedom and progress in the family: reflections on care, gender and inequality. Critical Horizons 2015;16:170-86.

42 Dahl HM, Stoltz P. Recognition, redistribution and representation in capitalist global Society: an interview with Nancy Fraser. Acta Sociologica 2004;47:374-82.

43 Wilson V, McCormack B. Critical realism as emancipatory action: the case for realistic evaluation in practice development. Nurs Philos 2006;7:45-57.

44 Hossen MA, Westhues A. Rural women's access to health care in Bangladesh: swimming against the tide? Soc Work Public Health 2011;26:278-93.

45 Abdulraheem IS. Health needs assessment and determinants of health-seeking behaviour among elderly Nigerians: a house-hold survey. Ann Afr Med 2007;6:58-63.

46 Longtin Y, Sax H, Leape LL, et al. Patient participation: current knowledge and applicability to patient safety. Mayo Clin Proc 2010;85:53-62.

47 Pronovost $\mathrm{P}$, Needham D, Berenholtz S, et al. An intervention to decrease catheter-related bloodstream infections in the ICU. $N$ Engl $J$ Med 2006;355:2725-32.

48 Hamiduzzaman M, Taylor A, Lunnay B. Challenges and solutions for collecting data in health research: experiences of Australian doctoral and early career researchers. In: Field guide for research in community settings. Northampton: Edward Elgar Publishing, 2021.

49 McLaren H, Patmisari E, Hamiduzzaman M, et al. Respect for religiosity: review of faith integration in health and wellbeing interventions with Muslim minorities. Religions 2021;12:692.

50 Rahman MM, Hamiduzzaman M, Akter MS, et al. Frailty indexed classification of Bangladeshi older adults' physio-psychosocial health and associated risk factors- a cross-sectional survey study. BMC Geriatr 2021;21:1-10.

51 Rahman MM, Farhana Z, Uddin MT. Nutritional vulnerability and associated risk factors estimation of Bangladeshi wetland community people aged 50 years and over. Research Square 2021.

52 Paul GK, Rahman MM, Hamiduzzaman M, et al. Hypertension and its physio-psychosocial risks factors in elderly people: a cross-sectional study in north-eastern region of Bangladesh. J Geriatr Cardiol 2021;18:75-82.

53 Bangladesh Bureau of Statistics. Adjusted Population and Housing Census 2011. Dhaka; Government of the People's Republic of Bangladesh, 2015. Available: http://bbs.portal.gov.bd/sites/default/ files/files/bbs.portal.gov.bd/page/7b7b171a_731a_4854_8e0a_ f8f7dede4a4a/PHC2011PreliminaryReport.pdf

54 Uddin MN, Hamiduzzaman M. Problems and prospects of decentralized rural health care system in Bangladesh. SUST J Public Administration 2009 https://www.academia.edu/9020040/The Problems_and_Prospects_of_Decentralized_Rural_Health_Services_ System_in_Bangladesh

55 Hamiduzzaman M, De Bellis A, Kalaitzidis E. Factors impacting on elderly women's access to healthcare in rural Bangladesh. Indian $J$ Gerontology 2016;30.

56 Hamiduzzaman M. Self-reported seasonal symptoms and diseases and primary healthcare utilization among rural elderly women in Sylhet district, Bangladesh. J Uoeh 2020;42:175-85

57 Hossen A, Westhues A. In search of healing between two worlds: the use of traditional and modern health services by older women in rura Bangladesh. Soc Work Health Care 2012;51:327-44.

58 Deere CD, Oduro AD, Swaminathan $\mathrm{H}$, et al. Property rights and the gender distribution of wealth in Ecuador, Ghana and India. J Econ Inequal 2013;11:249-65.

59 Karim AZ. Women's property rights in Bangladesh: what is practically happening in South Asian rural communities. ITALIENISCH2020;10 http://italienisch.nl/index.php/VerlagSauerlander/article/view/63 